\section{Spontaneous breathing during anaesthesia: first, do no harm}

\author{
GORDON B DRUMMOND
}

\author{
GORDON B DRUMMOND $(\bowtie)$ \\ Department of Anaesthesia, \\ Critical Care and Pain Medicine \\ Royal Infirmary of Edinburgh \\ Little France Crescent \\ Edinburgh \\ EH16 4HA \\ United Kingdom \\ Phone: 441312423134 \\ Fax: 441312423138 \\ E-mail: g.b.drummond@ed.ac.uk
}

\begin{abstract}
Controlled respiration and mechanical ventilation have long been part of anaesthetic practice. Modern surgery, anaesthetic techniques, and new agents require a reappraisal of this established habit. In many circumstances the adverse effects of mechanical ventilation can be avoided by the use of the laryngeal mask and allowing spontaneous ventilation. In addition to the more prominent advantages, such as less sore throat, reliable assessment of anaesthetic depth, and good recovery, there may be more subtle advantages such as improved cardiopulmonary interaction, better distribution of ventilation, and reduced mechanically induced lung damage. Some of these advantages may be also applied during mechanical ventilation, by allowing continued muscle activity or continuously varying the size of the tidal breaths.Mechanical ventilation is often unnecessary and may be harmful.
\end{abstract}

Keywords:respiration, neuromuscular blockade, artificial respiration, pulmonary gas exchange

\section{Introduction}

What factors affect the way anaesthetists choose their techniques? In large part, training and subsequent habit may be responsible. The availability of equipment and different drugs may also alter their choices, or even, in the subservient, the opinions and preferences of the surgeon: only rarely is scientific evidence used to inform them. Textbooks are excellent sources of "eminence based" advice, and only rarely offer substantiation.

Endotracheal intubation for anaesthesia was popularised by Ivan Magill and Stanley Rowbotham. They developed the apparatus used for "insufflation anaesthesia" where gases were blown into the trachea though a narrow tube, and allowed to spill out through the otherwise open airway. This technique proved unsatisfactory for anaesthetising patients undergoing plastic surgery to the head and neck, victims of injuries from the 1914-18 war. A wider tube allowing to and fro motion of the gases was better. They reported a case series of 3000 in 1921, and passed on their expertise to many, including Harold Griffith, who went on to present his own series of more than 1,500 cases ten years later. (1) It was Harold Griffith who later introduced curare into clinical practice in 1942. Long before he made this seminal advance, he had recognised the value of endotracheal intubation, not for head and neck procedures, but to provide good operating conditions during abdominal surgery. Without relaxants, he and others such as Guedel were rendering patients apnoeic and "relaxed" with cyclopropane, and manually providing positive pressure ventilation. In large part it was his familiarity with these methods that gave him the confidence to use muscle relaxants so well. (1)
We live and work in a different age: what reasons do we have, today, to place endotracheal tubes, paralyse and mechanically ventilate? There are many, but I suspect that the most potent are that it's possible, usually easy, convenient, and secure. This review will consider some of these aspects, and go on to consider some possible disadvantages which are less frequently considered. I make some suggestions to support spontaneous ventilation during anaesthesia as a better option for many patients.

Homeostasis is a concept popularised by Claude Bernard. (2) He argued that a constant internal environment was important for the survival of free-living animals, exposed to wide variations in their external environment. Medicine has been markedly affected by this dictum, and many anaesthetists strive to keep their patients "normal". Since anaesthesia itself already represents a "physiological trespass" (3), the aim 
$\mathrm{V}_{\mathrm{D}} / \mathrm{V}_{\mathrm{T}}$ ratio

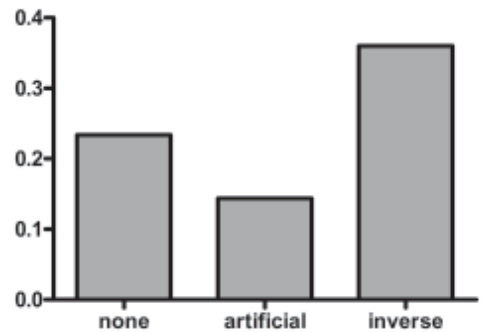

\section{$Q_{s} / Q_{T}$ ratio}

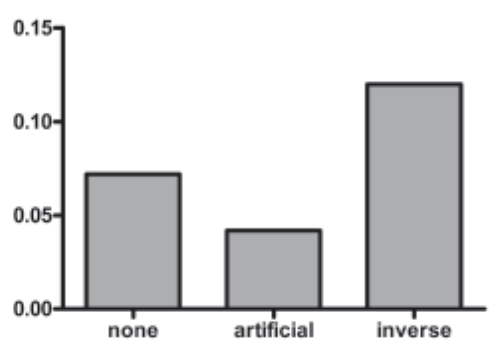

Figure 1. The effects of sinus arrhythmia on gas exchange in anaesthetised dogs: the rhythm changes were either removed, restored artificially by vagal nerve stimulation or reversed. Gas exchange is optimal with the normal pattern. Data from Hayano, Yasuma, Okada, et al. Circulation 199694 842-7

of these anaesthetists is to maintain alveolar ventilation and pulmonary gas exchange by mechanical ventilation, and additional interventions such as positive end-expiratory pressure, despite any convincing data to demonstrate improved outcome. Homeostasisnormal values - has become a desirable outcome although rarely a proven benefit

In fact, in some respects mechanical ventilation appears to be less efficient. Chest wall movement and regional ventilation are very different during mechanical ventilation (4), and measures of gas exchange efficiency such as deadspace and shunt are not improved. $(5,6)$ In part this may be caused by altered distribution of ventilation, but blood flow distribution may also be affected. For example, the natural link between heart rate and the respiratory cycle (sinus arrhythmia) is disturbed by imposing mechanical ventilation. If this link is abolished or reversed, the efficiency of gas exchange is reduced (figure 1). (7)

Although the link between respiration and heart rate, predominantly by lung stretch gating cardiac vagal efferents, is widely accepted, a link between cardiac activity and the initiation of inspiration is less well known. However during natural sleep, sedation, and anaesthesia, this link is frequently apparent. (8) A heart beat triggers the onset of a breath, so that there is often an integer ratio between heart beats and breath cycles, say 3 beats per cardiac cycle, and changes in breath duration appear to be in "units" of car- diac cycles (figure 2). The value, if any, of this link remains unclear. The likely feature is that this too will improve gas exchange, as does sinus arrhythmia, but this is not yet proven. However there is no doubt that regular mechanical ventilation will prevent it.

Regular mechanical ventilation also exposes the lung to damage. Particularly in patients with lungs that are already exposed to damaging factors, such as sepsis, mechanical ventilation is harmful. This damage can be caused both by excessive stretch of lung tissue (9), and also by high flow rates through airways at low lung volumes. $(10,11)$ However, even if steps are taken to minimise these effects, the mere regularity of mechanical ventilation appears

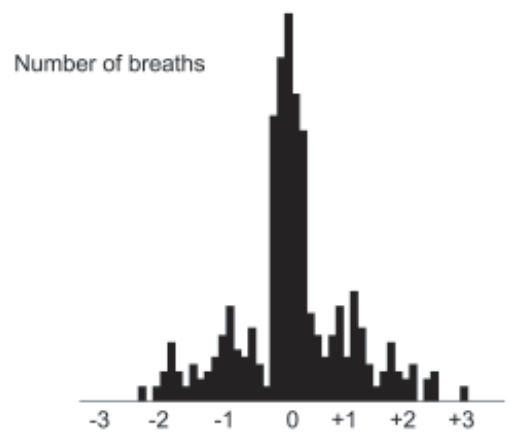

Change in breath cycle length (heart beat periods)

Figure 2. Distribution of breath duration in normal subjects during isoflurane anaesthesia. Breath duration is related to the heart rate in a quantal fashion. Data modified from Larsen, Tzeng and Galletly, Br J Anaesth 2003 91,184-9 to cause harm by the repeated application of stress to the same parts of the lung tissue. If the size and duration of the breaths are continuously changed so that the distribution of tidal volumes represents normal statistical variability, then the impact on lung function is prevented (figure 3). (12,13) Although patients breathing spontaneously during anaesthesia have a more stable respiratory pattern than while awake, their respiration does vary spontaneously, and this is sufficient to prevent deterioration in lung function.

Another factor that appears to improve lung function, even when ventilation is predominantly artificial, is the persistence of activity in the respiratory muscles. For example, Hedenstierna and colleagues showed that stimulation of the diaphragm during anaesthesia could reduce the degree of atelectasis that occurred during mechanical ventilation (14) and that spontaneous breathing allowed better gas exchange than mechanical ventilation (figure 4). (6) Animal studies show that persistent diaphragm activity ameliorates the effects of mechanical ventilation. (15) It seems that many of the features of normal breathing: muscle activity, variation in breath size, and coordination of the heart with the respiratory cycle, offer advantages in terms of lung function. Are there equivalent disadvantages that can we avoid, by allowing our patients to breathe?

The enormous success of the laryngeal mask (LMA) has clearly rejuvenated interest in spontaneous breathing. The results of lung function tests are better after surgery when the LMA is used, in contrast to the endotracheal tube (16), probably because of less tracheal irritation. Since insertion doesn't require muscle paralysis, there is much less obligation to mechanically ventilate. Even when mechanical ventilation is applied during laparoscopy, there appears to be no difference in outcome between patients that are intubated and those in whom an LMA is used. (17) A further advantage of avoiding muscle relaxants is that we can avoid the consequences of incomplete reversal, 


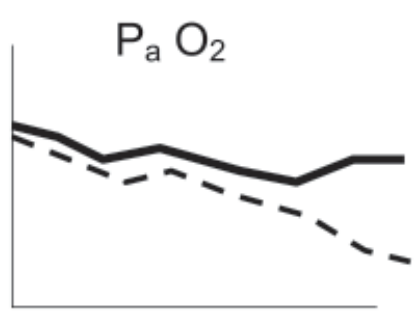

$$
Q_{S} / Q_{T}
$$

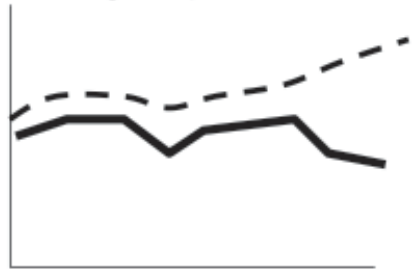

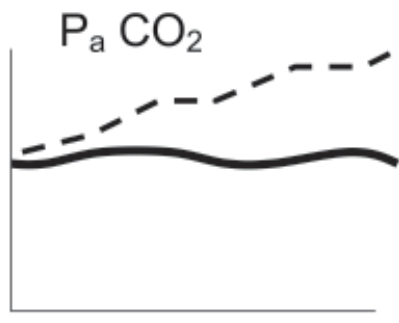

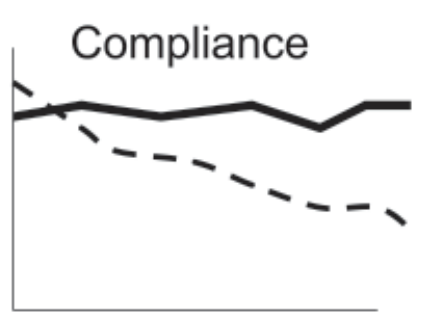

Figure 3. The effects of prolonged ventilation during anaesthesia on lung function. The dashed line indicates the effects of regular uniform ventilatory pattern: the solid line indicates ventilation with a variable pattern, where tidal volume varied and frequency varied reciprocally to maintain a constant exhaled minute volume. Gas exchange efficiency gradually deteriorates with regular ventilation. Data from Mutch et al (2000) Br J Anaesth 84 197-203

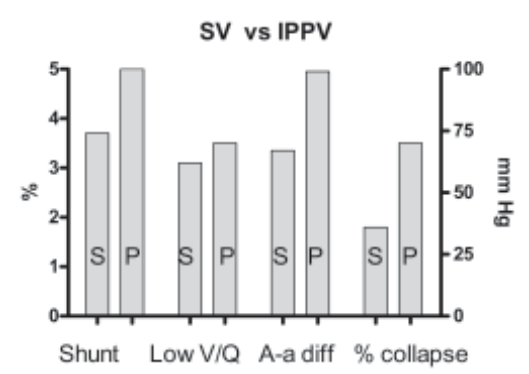

Figure 4. Measures of lung performance comparing anaesthesia with spontaneous ventilation (columns marked S) and with muscle paralysis and ventilation (columns marked $\mathbf{P}$ ). paralysis and mechanical ventilation is associated with more atelectasis, and impaired gas exchange. Data from Tokics et al Anesthesiology 198766 157-167

which remains a common problem (18) (figure 5) although things do seem to be getting better. (19) An advantage that is often claimed for the endotracheal tube is protection from aspiration of gastric contents. Although in many emergency circumstances an endotracheal tube is prudent, in routine elective clinical practice, regurgitation of gastric content

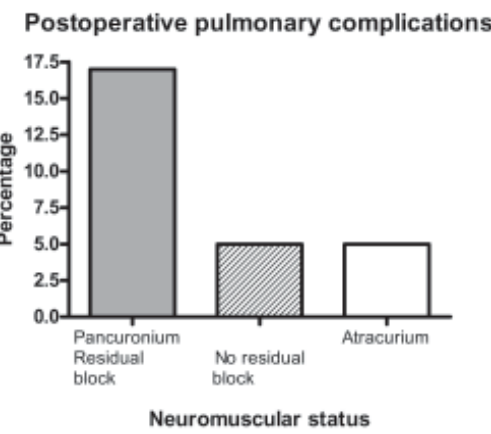

Figure 5. Pulmonary complications are frequent if incomplete neuromuscular block is present at the end of surgery. Data from Berg et al.. Acta Anaesth Scand 1997; 41: 1095-103.

is rare and adverse effects even less common. (20)

However there is no doubt about one advantage of not using muscle relaxants and allowing patients to breathe: we have no doubt that they are properly anaesthetised! Patients continue to worry that they may be aware during anaesthesia. They are considerably more reassured when they are told that they will not receive relaxants, and that any signs of inadequate anaesthesia would be promptly apparent and easily recognised, rather than having to be reliant on more subtle signs and developing technology which is not $100 \%$ reliable. (21) When we avoid relaxants and use the anaesthetic to immobilise as well as obtund, then we can be sure that the patient is unconscious. This is true of volatile agents, (figure 6) and injected agents such as barbiturates and propofol $(22,23)$ but may not be so when large doses of opioids are given. Much modern anaesthesia is carried out on a day case basis (24), and much of this is conducted using the laryngeal mask. (25) In these circumstances, spontaneous ventilation is a simple and practical strategy. No doubt, the milieu intérieure may change a little: respiratory depression and hypercapnia are almost inevitable. However there is no evidence that this is harmful: indeed some evidence shows that the subcutaneous circulation, important for wound healing, may be better perfused and oxygenated in these circumstances (26) although there is to date no direct evidence that wound healing or wound infection rates are affected.

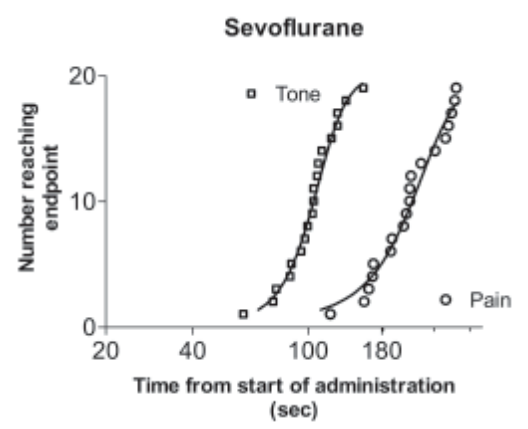

Figure 6. Cumulative distribution of time of onset of two features of anaesthesia during inhalation induction. Square symbols: loss of muscle tone in the arm. Round symbols: loss of motor response to painful stimulus. Note the lack of overlap of the two features. Data from Thompson and Drummond, $\mathrm{Br} \mathbf{J}$ Anaesth (2001) 87 203-6 
So Claude Bernard's milieu may be disturbed, at least a little, if we let our patients breathe for themselves, but there is no doubt that this great scien- tist had another, perhaps more important message that we should follow: "L'expérimentateur doit douter, fuir les idées fixes, et garder toujours sa liberté d'esprit" (The experimenter should doubt, discard preconceptions, and always keep an open mind).

\section{REFERENCES}

1. Bodman R, Gillies D. Ethylene and endotracheal anaesthesia. In: Harold Griffith, editor. The evolution of modern anaesthesia. Toronto: Hannah and Dundurn; 1992;4:39-48.

2. Bernard C. Introduction à l'étude de la médecine expérimentale. 1865

Accessed at www. gutenberg.org/etext/16234.

3. Gillies J. Physiological trespass in anaesthesia. Proc Roy Soc Med 2007; 45:1-6.

4. Marsh HM, Rehder K, Sessler AD, Fowler WS. Effects of mechanical ventilation, Muscle Paralysis, and Posture on Ventilation-Perfusion relationships in Anesthetized man. Anesthesiol 1973;38:59-67.

5. Nunn JF, Hill DW. Respiratory deadspace and arterial to end tidal $\mathrm{CO}_{2}$ tension difference in anesthetized man. J Appl Physiol 1960;15:383-9.

6. Tokics L, Hedenstierna G, Strandberg A, Brismar B, Lundquist H. Lung collapse and gas exchange during general anesthesia: effects of spontaneous breathing, muscle paralysis, and positive end-expiratory pressure. Anesthesiol 1987; 66:157-67.

7. Hayano J, Yasuma F, Okada A, Mukai S, Fujinami T. Respiratory sinus arrhythmia - phenomenon improving pulmonary gas- exchange and circulatory efficiency. Circulation 1996;94:842-7.

8. Larsen PD, Tzeng YC, Galletly DC. Quantal ventilatory variability during spontaneous breathing anaesthesia. Br J Anaesth 2003;91:184-9.

9. Dreyfuss D, Saumon G. Role of tidal volume, FRC and end-inspiratory volume in the development of pulmonary edema following mechanical ventilation. Am Rev Respir Dis 1993;148:1194-203.

10. Nucci G, Suki B, Lutchen K. Modeling airflow-related shear stress during heterogeneous constriction and mechanical ventilation. J Appl Physiol 2003; 95:348-56.

11. D'Angelo E, Pecchiari M, Saetta M, Balestro E, Milic-Emili J. Dependence of lung injury on inflation rate during low-volume ventilation in normal open-chest rabbits. J Appl Physiol 2004;97:260-8.

12. Mutch WAC, Eschun GM, Kowalski SE, Graham MR, Girling LG, Lefevre GR. Biologically variable ventilation prevents deterioration of gas exchange during prolonged anaesthesia. Br J Anaesth 2000;84:197-203.

13. Boker A, Haberman CJ, Girling L, Guzman RP, Louridas G, Tanner JR et al. Variable ventilation improves perioperative lung function in patients undergoing abdominal aortic aneurysmectomy. Anesthesiol 2004;100:608-16.

14. Hedenstierna G, Tokics L, Lundquist $H$, Adresson $T$, Strandberg A, Brismar B. Phrenic-nerve stimulation during halothane anesthesia. Anesthesiol 1994;80:751-60.

15. Bregeon F, Delpierre S, Roch A, Kajikawa O, Martin TR, Utillo-Touati A et al. Persistence of diaphragmatic contraction influences the pulmonary inflammatory response to mechanical ventilation. Respiratory Physiology \& Neurobiology 2004;142:185-95.

16. Natalini G, Franceschetti ME, Pletti C, Recupero D, Lanza G, Bernardini A. Impact of laryngeal mask airway and tracheal tube on pulmonary function during the early postoperative period. Acta Anaesth Scand 2002;46:525-8.

17. Maltby JR, Beriault MT, Watson NC, Liepert DJ, Fick GH. LMA-Classic (TM) and LMA-ProSeal (TM) are effective alternatives to endotracheal intubation for gynaecologic laparoscopy. Canadian Journal of Anaesthesia-Journal Canadien D Anesthesie 2003;50:71-7.

18. Viby-Mogensen J. Editorial I - Postoperative residual curarization and evidence-based anaesthesia. Br J Anaesth 2000;84:301-3.

19. Baillard C, Clec'h C, Catineau J, Salhi F, Gehan G, Cupa M et al. Postoperative residual neuromuscular block: a survey of management. Br J Anaesth 2005;95:622-6.

20. Warner MA, Warner ME, Weber JG. Clinical significance of pulmonary aspiration during the perioperative period. Anesthesiol 1993;78:56-62.

21. Practice advisory for intraoperative awareness and brain function monitoring - A report by the American Society of Anaesthesiologists task force on intraoperative awareness. Anesthesiol 2006;104:847-64.

22. Strickland TL, Drummond GB. Comparison of pattern of breathing with other measures of induction of anaesthesia, using propofol, methohexital, and sevoflurane. Br J Anaesth 2001;86:639-44.

23. Thompson S, Drummond GB. Loss of volition and pain response during induction of anaesthesia with propofol or sevoflurane. Br J Anaesth 2001;87:283-6.

24. Payne K, Moore EW, Elliott RA, Pollard BJ, McHugh GA. Anaesthesia for day case surgery: a survey of adult clinical practice in the UK. Eur J Anaesth 2003;20:311-7.

25. Simpson RB, Russell D. Anaesthesia for daycase gynaecological laparoscopy: a survey of clinical practice in the United Kingdom. Anae 1999; 54:72-6.

26. Hager H, Reddy D, Mandadi G, Pulley D, Eagon JC, Sessler DI et al. Hypercapnia improves tissue oxygenation in morbidly obese surgical patients. Anesthesia and Analgesia 2006;103:677-81. 